\title{
CARCINOMA OF THE THYROID GLAND IN GHILDHOOD
}

\author{
WITH REPORT OF A GASE
}

\author{
BY \\ A. BRIAN TAYLOR, M.D., M.R.C.P. \\ (Physician to Out-Patients, Queen's Hospital, Birmingham; late \\ House Physician, Belgrave Hospital for Children, London), \\ AND \\ B. M. WILKINSON, M.B., B.S. \\ (Acting Pathologist, Belgrave Hospital for Children).
}

Malignant growths of the thyroid gland have been well studied recently, but their occurrence at ages below 20 or 30 remains rare and interesting. It is generally agreed that the fourth to sixth decades are those in which carcinoma is most usually met; in the literature there are only a small number of cases reported under the age of 30 , and it seems to be exceptional under the age of ten. The present case occurring at the age of six is, therefore, of some interest, especially as it caused difficulty in diagnosis owing to the predominant features of the pulmonary metastases.

Hughes $^{1}$, in 1920, reported a case occurring in a girl of 13 who had had a mid-line swelling in the neck for three years, but with no obstructive symptoms. A group of glands was removed from the right side of the neck and showed replacement by papilliferous carcinoma. The thyroid tumour was then removed with difficulty and showed the same changes. Three months later the child was well. Blaxland ${ }^{2}$ operated on a girl of 25 who had had the right lobe of her thyroid removed when 19 for a parenchymatous goitre which was confirmed microscopically. He excised the left lobe for further pressure symptoms and section then showed the presence of adeno-carcinoma in one area. A year later the patient was well. Schultz ${ }^{3}$ records a case of a girl of five-and-a-half years. Atypical thyroid tissue of highly malignant character had invaded the capsule, surrounding tissue and lymph-nodes. The child was still well nineteen months after removal of the tumour and roentgen irradiation. He emphasizes the facts, also mentioned in Hughes' paper, that this type of neoplasm seems less malignant and less liable to infiltrate than the similar growths of older persons. Ewing ${ }^{4}$, in an extensive discussion of the pathology of the condition, gives the general age of 50-60 as the usual one, and extremes of $10-90$, but quotes a case recorded by Demme in a boy of five. In 1929 specimens were shown at the Royal Society of Medicine by Moncrieff ${ }^{5}$ from a girl of 11 , who had been under the care of Dr. F. J. Poynton. She had been noticed to have a swelling in the neck since the age of four, but only in the last few months had it enlarged 
and caused noisy respiration. An operation was attempted owing to urgent obstructive symptoms, but adhesions, especially to the deep layers, caused difficulty and the child died soon after. On microscopical examination of the superficial parts of the gland typical parenchymatous goitre was seen, but deeper there were definite malignant changes, partly papilliferous, partly solid carcinoma, with infiltration of the trachea, and other structures. Cattell ${ }^{6,7}$ has recorded four cases in children. The first of these, in a girl of eleven years, had lumps in the right side of her neck which had appeared one-and-a-half years previously. Nine months before a biopsy had shown non-malignant glands, but six months subsequently it was repeated and thyroid papillary-cystadenoma was found. A radical dissection was carried out, including the jugular vein, and the right lobe and isthmus of the thyroid itself. The histology was confirmed, and postoperative x-ray treatment was given. A year later the patient was healthy. He also had another case in a girl of eleven years with nodules of papillary-cystadenoma in an aberrant thyroid and one lobe of the main gland. She, too, was well two years after eradication associated with x-ray therapy. In another case growth was found in the wall of a thyroglossal cyst in a boy of six, who was well fifteen months after its surgical removal. The fourth case is more like the case to be described here, and that reported by Poynton and Moncrieff. A boy of 13 developed a hard mass in one lobe of the thyroid, shortness of breath, respiratory wheeze and stridor. The trachea, by $x$-rays, was seen to be deviated and narrowed. A highly malignant, small-celled carcinoma, histologically resembling lymphosarcoma, was removed and $\mathrm{x}$-ray therapy was given, but recurrences appeared in the chest and the boy died. Dunhill ${ }^{8}$ reported the occurrence of lateral, aberrant thyroid nodules in the neck of a patient of sixteen, who was known to have had lumps there since he was twelve. The thyroid was enlarged, but quite separate. Microscopically the nodules consisted of papilliferous growth into cystic spaces, some of which contained colloid. He classed them as papillary-cystadenomata, with a tendency to undergo malignant transformation. Griffith and Mitchell ${ }^{9}$ emphasize the rarity of these tumours in children, but note that aberrant thyroid tissue may develop tumour masses and cysts, into which class of case those of Cattell and Dunhill can be included. Pemberton and Dixon ${ }^{10}$ in a paper summarizing the end-results of treatment of various forms of malignancy, mention the age incidence of 323 cases of thyroid malignancy, of which two are under nine, and eight more between ten and nineteen. It is possible that here are included malignant tumours, other than carcinoma, such as sarcoma, which may occur less rarely in childhood. Lee $^{11}$ reported a case of carcinoma of the thyroid in a child of eight years. Schreiner and Murphy ${ }^{12}$, in a paper on malignant neoplasms of the thyroid, have investigated some of the literature on cases occurring in younger patients. They cite eight cases below the age of 30 , but only half of these are under 20: Bérard ${ }^{13}$ reported the condition in a girl of eighteen, Müller ${ }^{14}$ in a boy of eighteen, Meleney ${ }^{15}$ in a boy of seventeen, and Hughes' case, already mentioned, in a girl of thirteen.

These reports show that carcinoma of the thyroid does occur in childhood, but that it is unusual and arouses special interest. All the authors and other authorities are agreed that it is usually to be considered a disease of persons over 40. In a few of these cases quoted the condition has arisen in aberrant masses of thyroid tissue in the neck, and several have emphasized a pre-existing goitre, as sometimes occurs at the later ages. 


\section{Pathology.}

From the pathological point of view these growths fall into two groups. In one they seem to run a relatively benign course and the malignant nature may only be found after histological examination, infiltration and glandular invasion not having been seen at operation. A number of these have been referred to, and operation combined with x-ray therapy has mainly given good results within periods up to a year or two. On the other hand, some of the cases, notably that described by Poynton and Moncrieff, Cattell's fourth case and our case, described below, are of much more rapid evolution with infiltration of the trachea, neck tissues and glands, producing respiratory obstruction. Operation, often in a rather vain hope, is difficult and unsatisfactory. These cases run a much more rapid course, and by the time a diagnosis can be arrived at and treatment considered it is already too late. Death from asphyxia or exhaustion, due to partial asphyxia, occurs, while the general nutrition remains little impaired.

Another interesting difference between the two groups is in regard to metastases. Whereas in the one the growth has remained local, the other often shows at autopsy multiple metastases, and in this conform to the adult type. The lungs are particularly susceptible, and secondary deposits may be either large and few or small and disseminated. The occurrence of the latter type in our case, appearing radiologically very like miliary tuberculosis, caused much difficulty in diagnosis before the mass in the thyroid became visible, palpable or remarkable by its symptoms. The ready invasion of the veins and lymphatics so closely in relation to the rapidly infiltrating growth is given as the usual explanation of the early appearance of metastases and their wide distribution. Ewing states the order of frequency of these in 238 cases was : lungs, bones, liver, kidneys, pleura, brain and elsewhere. There is a plate in his book of a skiagram to show multiple pulmonary metastases of miliary type, similar to the one of our case reproduced here, though showing less isolation of the multiple foci.

Histologically, the classification of primary thyroid carcinomata at all ages has been clarified by $\mathrm{Joll}^{16}$, who divides them into three groups :-

(1) malignant adenoma; (2) papilliferous carcinoma; and (3) carcinoma simplex.

Most of these reported cases in children appear to fall into one of the first two groups and it appears significant that those which by their reports are of the adenomatous type, are also of that group-less malignant, more localized and with a better prognosis-described above. On the other hand where a papilliferous carcinoma has been found the other, much more serious group seems to correspond, with early infiltration and metastasis. The case reported here is of this type and the microphotographs and pathological report are typical of this growth. The case reported by Poynton and Moncrieff was illustrated by a microphoto- 
graph showing this type though also in parts there was solid carcinoma. A point of interest in connection with the metastases is that they may function as normal thyroid tissue after thyroidectomy although microscopically they may appear either non-malignant or similar to the original growth.

\section{Case history.}

The patient, a well-built girl of six years and three months, came to the out-patient department of the Belgrave Hospital for Children in May,

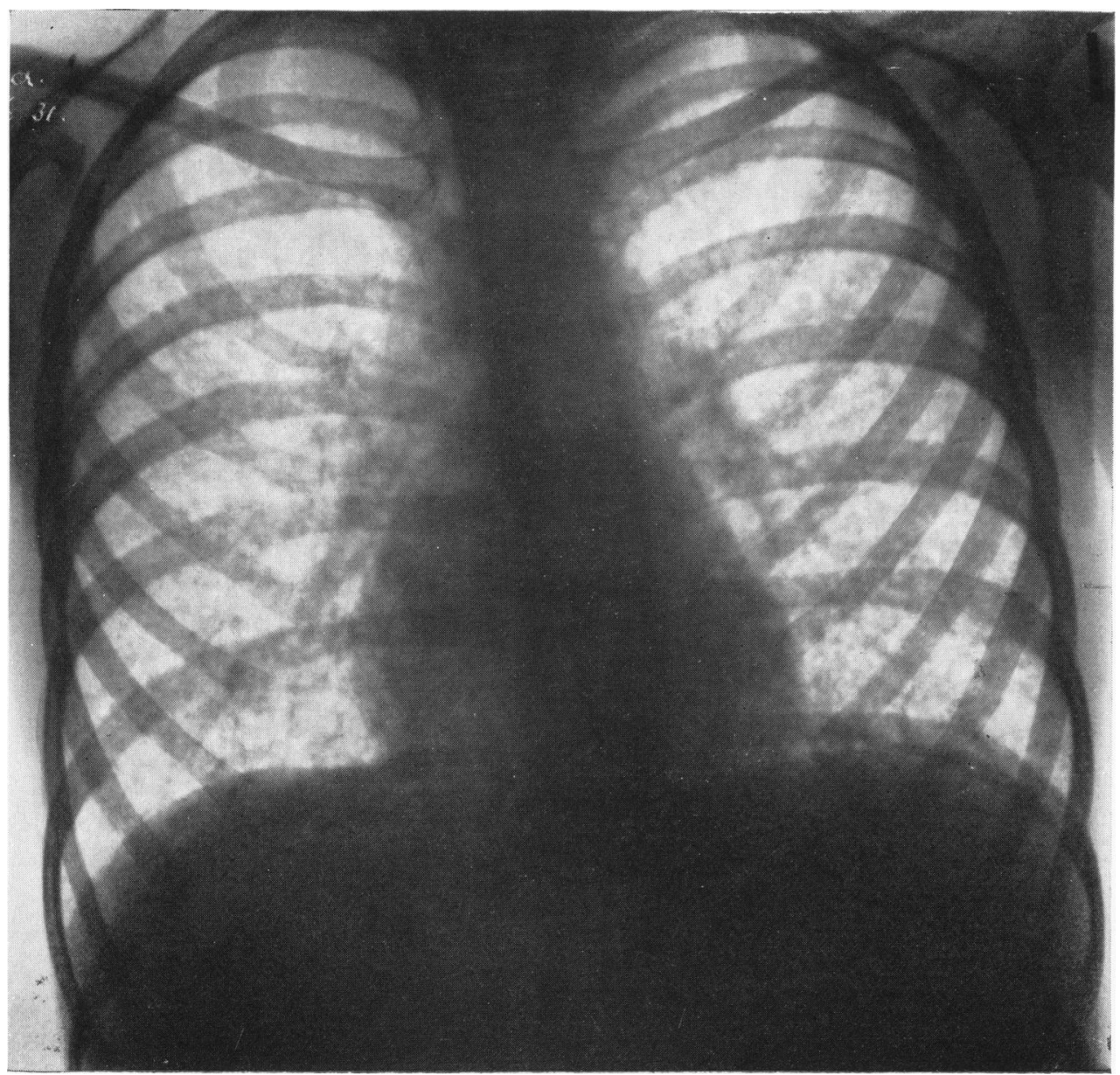

FIG. 1.-X-ray picture of lungs showing miliary metastatic deposits.

1931, complaining of a cough of five weeks' duration following a cold. There was some shortness of breath and occasionally a little expectoration, but never haemoptysis. Her general health had not altered though she had not been strong since an attack of food poisoning a year before.

Examination revealed only the presence of a number of small, discrete, 
hard glands in the neck, and in view of the cough the chest was x-rayed, revealing appearances suggestive of miliary tuberculosis (fig. 1). The patient was therefore admitted to hospital on May 21. The cough had, by then, become more of a hoarse bark occurring in paroxysms and there was persistent shortness of breath.

The child preferred to sit up in bed; her breathing was harsh and noisy with an occasional dry, barking cough. Examination of the lungs

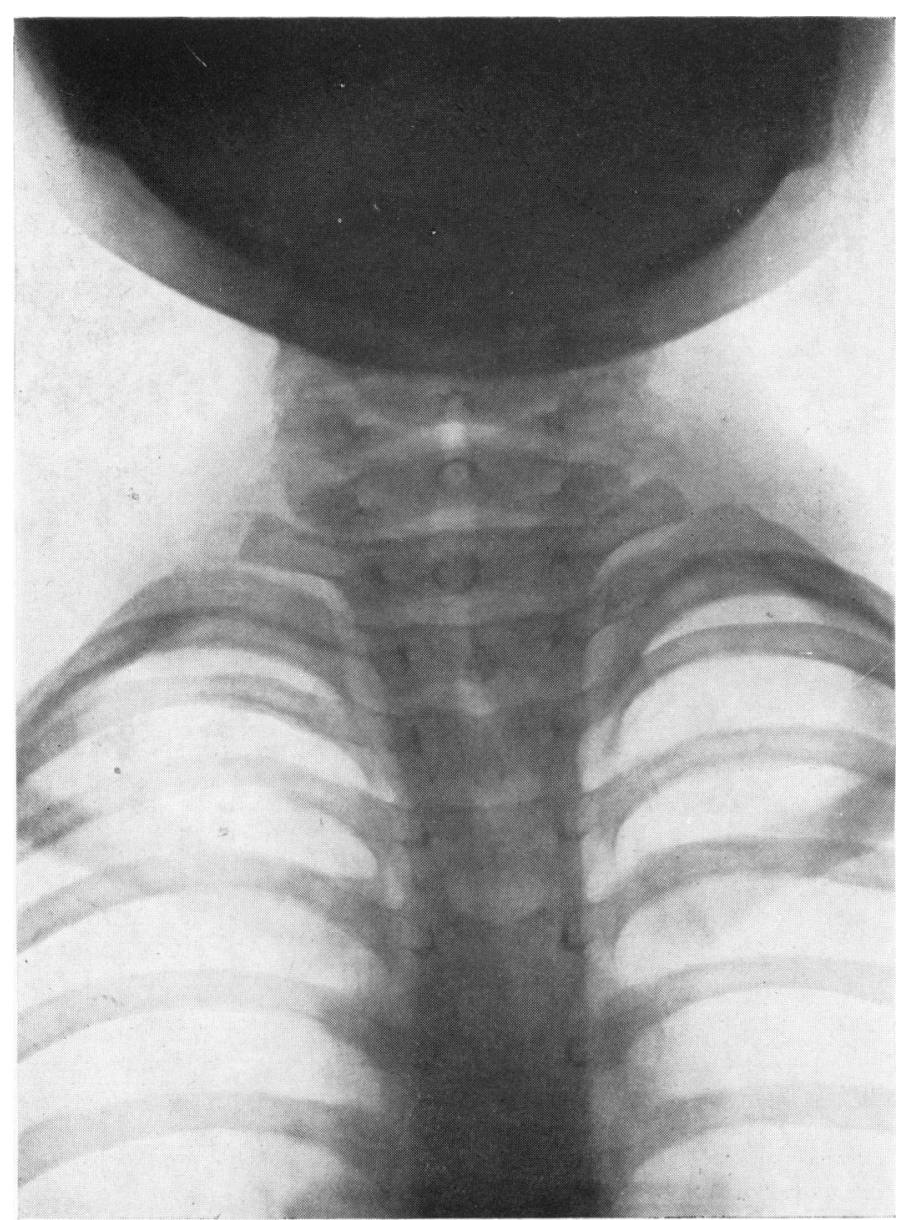

FIG. 2.-Skiagram of neck showing distortion of trachea by primary growth in thyroid.

showed mainly abdominal respiration with hollowing of the sternum. The resonance was high pitched and breath sounds were harsh, accompanied by scattered râles. The liver was palpable, but not enlarged, and the spleen was not felt. In the neck a number of firm, discrete glands were present on both sides in relation to the sterno-mastoids. The thyroid 
gland then felt normal. The temperature was subnormal and pulse between 80 and 110, respirations 24 to 28 . Her weight was $37 \mathrm{lb} .14 \mathrm{oz}$.

On June 8, the child was still apparently well though her breathing was hoarse. No gross abnormal signs were found in the chest and the glands in the neck remained hard and discrete. A Mantoux tuberculin reaction was carried out and was negative. At this point the diagnosis presented a considerable problem. The diminution of the cough, absence

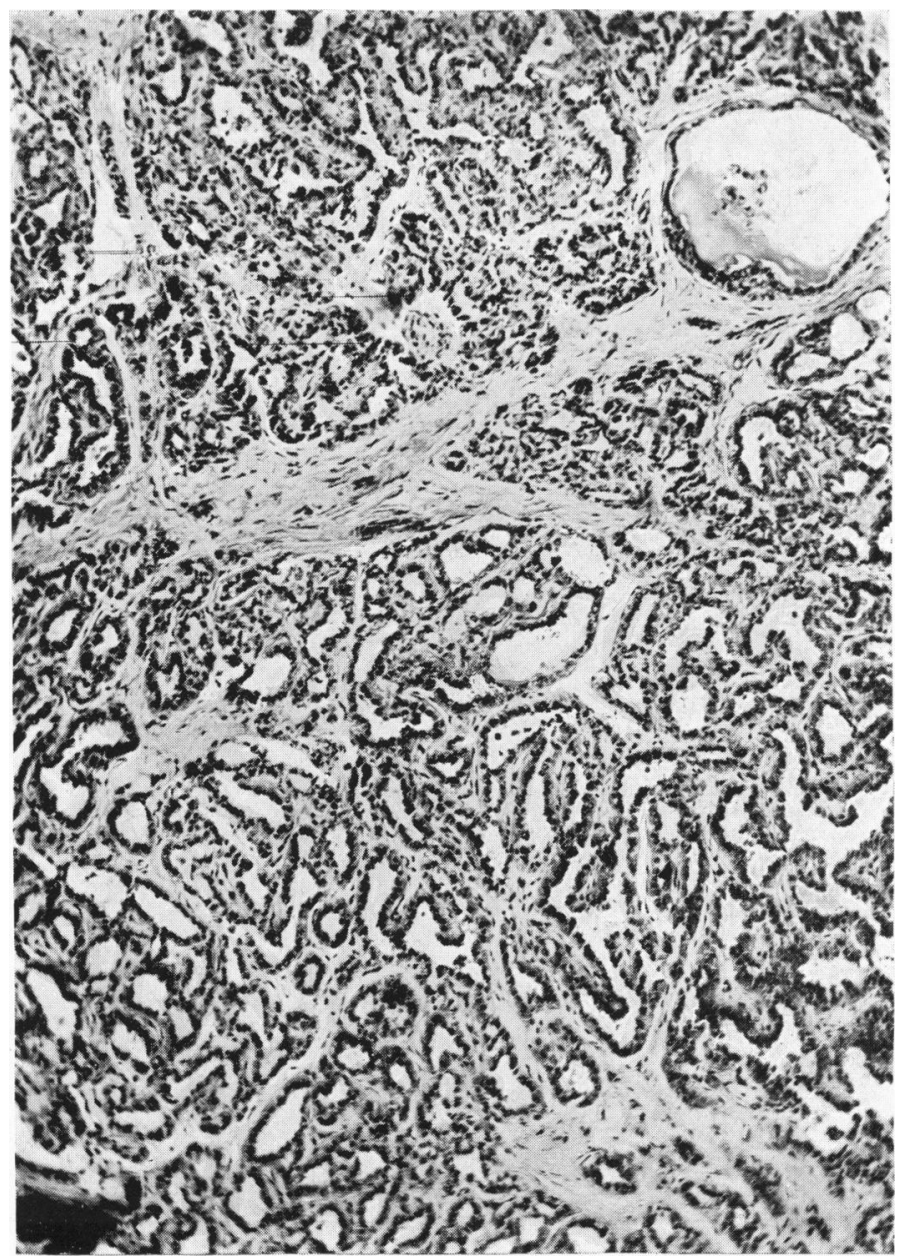

Fig. 3.-Section of growth in thyroid $\times 125$.

of sputum and temperature and the fact that the child was not in herself ill discredited the x-ray suggestion. Moreover the smallness of the glands and the absence of palpable thyroid changes did not attract attention thereto and the pulmonary condition, even in the absence of physical signs, was the centre of interest. 
By July 1, however, some alterations had occurred. Dyspnoea had become more marked and was accompanied by stridor. This appeared to be due to tracheal obstruction and a skiagram (fig. 2) showed narrowing and distortion of the upper part of the trachea. The cervical glands were also increasing. She was seen by Mr. Negus at King's College Hospital, and he confirmed the tracheal obstruction and considered that it was due to glandular enlargement which extended down into the

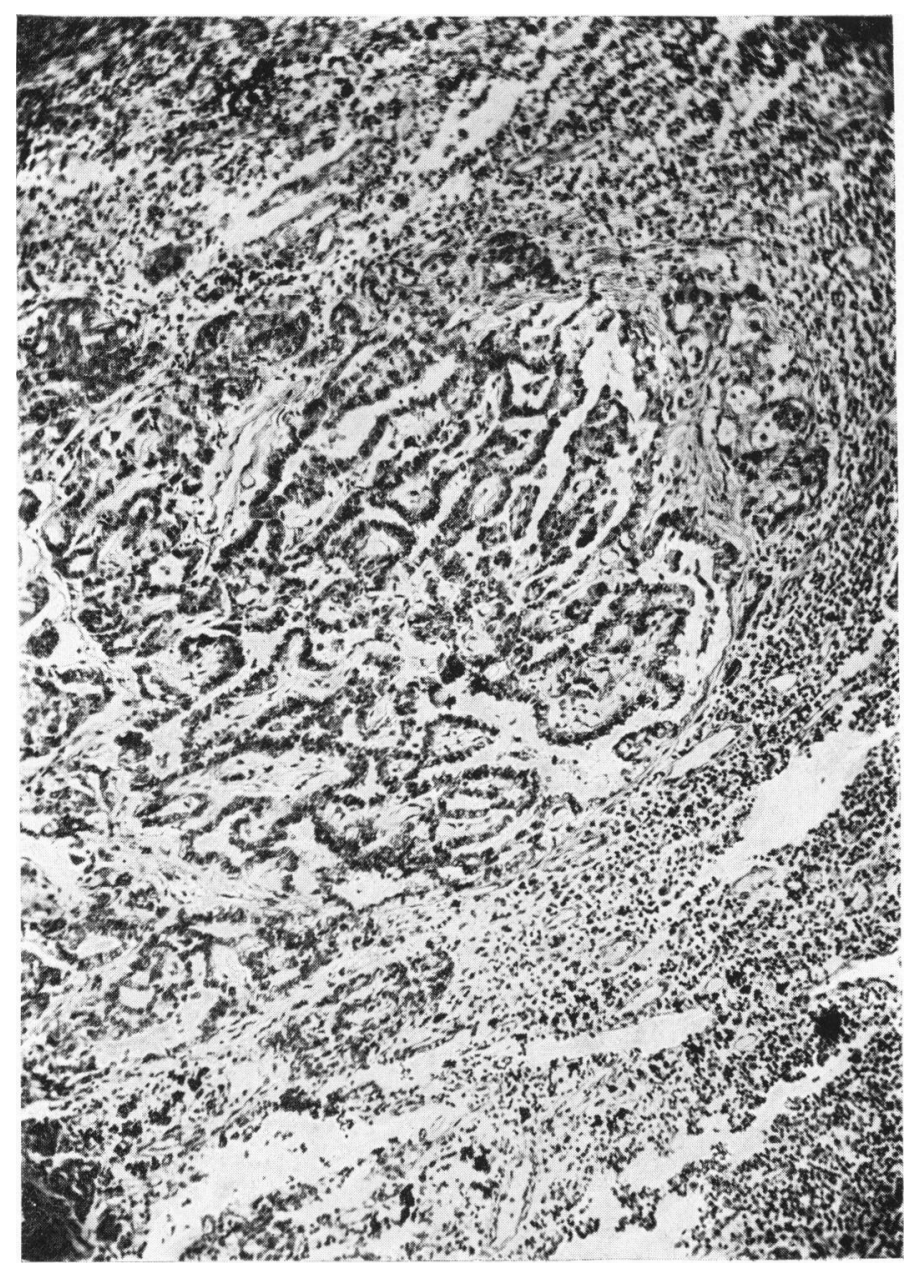

Fig. 4.-Section of bronchial gland $\times 125$.

mediastinum. At this point lymphadenoma and lymphosarcoma were suggested as possible diagnoses, although no other glands or the spleen could be felt.

The glands were fusing into a thick mass on both sides of the trachea and larynx, and dyspnoea was becoming more acute. The blood count 
showed 7,010,000 red corpuscles per c.mm. and 125 per cent. haemoglobin. The leucocytes were 24,000 per c.mm. During the last few days before death on July 16 her condition was distressing; orthopnoea occurred in attacks and was increasingly severe. Between attacks she recovered extraordinarily and would take nourishment. The fact that her weight was almost unaltered since admission showed how little general disturbance

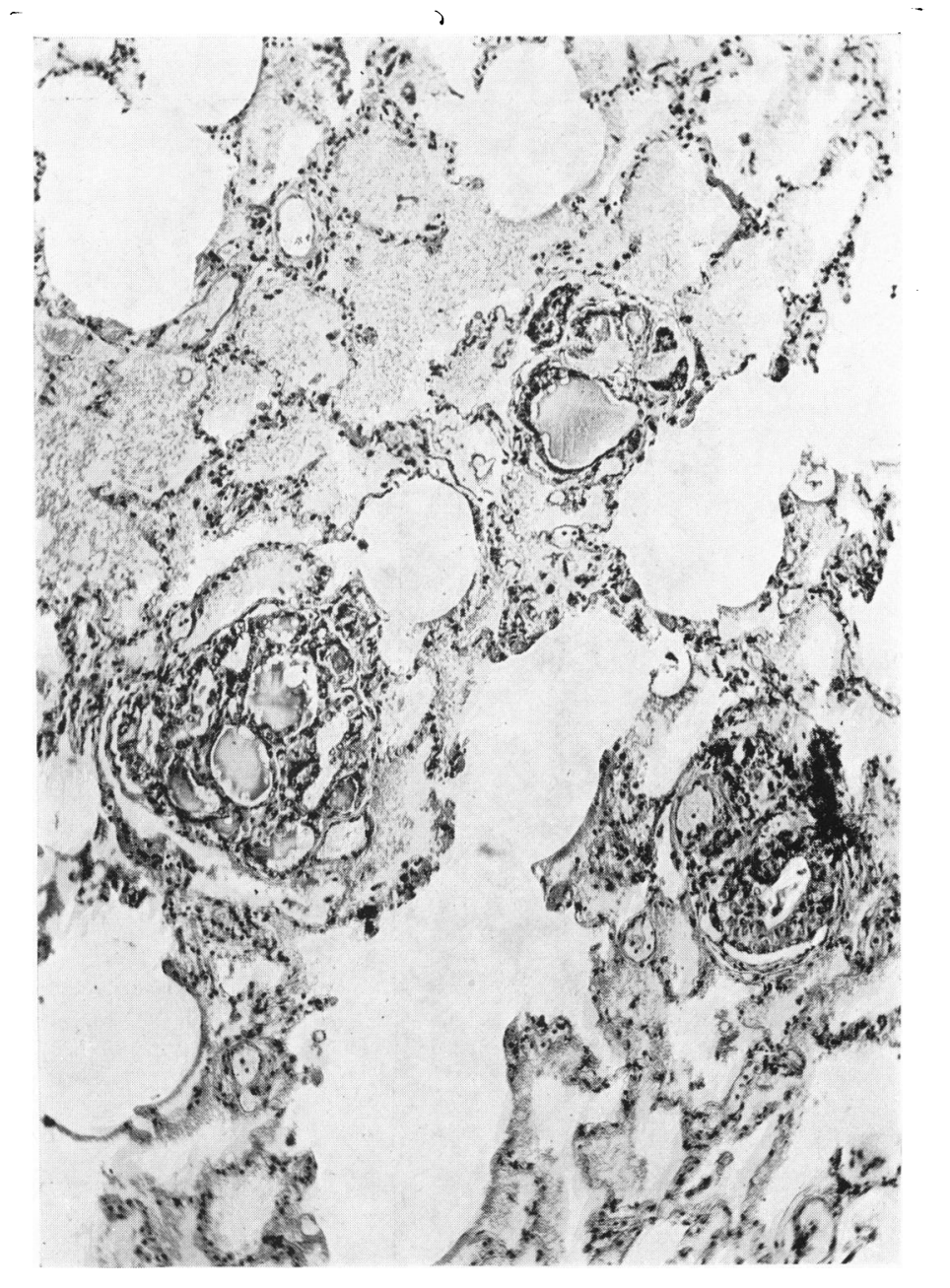

FIG. 5.-Section of metastasis in lung $\times 125$.

there was apart from the mechanical obstruction to breathing. Finally she died of asphyxia.

The skiagrams reproduced show the miliary metastatic deposits throughout the lungs very similar to those of miliary tuberculosis, and also the glandular enlargements at the hilum and in the mediastinum. The narrowing and distortion of the trachea can be seen extending as low as the fifth cervical vertebra. 
A post mortem examination was carried out; the body was that of a well-nourished girl and a mass of glands was palpable round the trachea; no other enlarged glands were felt. The thyroid was completely enclosed anteriorly; posteriorly it was found that both lobes were hard and enlarged, especially the right, and measured about $2 \frac{1}{2}$ inches across. It was adherent to the trachea and on making sections the lumen was found to be occluded partly by invasion and partly by compression, mainly at the level of the second and third rings, causing thereby the fatal asphyxia. The heart was normal except for dilatation of the right ventricle. The lungs were studded throughout with hard white nodules of growth varying in size from a pin's head to a pea. There was no evidence of caseation and apart from engorgement the lung substance was otherwise normal. In the neck there was a mass of enlarged glands round the upper part of the trachea, extending from the level of the larynx to the sternal notch and continued on, less extensively, into the bronchial glands. The glands were discrete, hard and of a uniform consistency. Some were the size of a walnut, but most were smaller. There was dense fibrous tissue between them. All the other organs were normal.

Histology. Much of the growth was similar to normal thyroid tissue, with abundant colloid formation. In other parts the vesicles became very irregular, containing papillary processes, and the colloid scanty (fig. 3). In a few places the cells were in masses, giving the appearances of a solid carcinoma. The cells were atypical cubicle or tending to columnar. The growth on the right side was invading the outer layer of the trachea. It appeared to be of the type of papillary carcinoma of Joll's classification.

Cervical glands.-These were extensively invaded by malignant growth. There was no collloid formation (fig. 4).

Lungs. - There were numerous deposits of thyroid carcinoma. Many of these reproduced the structure of a normal thyroid very accurately with colloid formation (fig. 5).

\section{Summary.}

The rarity of carcinoma of the thyroid in children is noted and a review of the literature is given. Two groups of cases appear to occur: one relatively benign and slow growing and more usually of adenomatous type histologically; the other rapidly malignant, readily metastazising and of papilliferous type histologically.

An example of this second type in a girl of six years is described in detail, in which the multiple pulmonary metastases seen by x-rays before the original growth became evident strongly suggested miliary tuberculosis, but later when this was clinically untenable the thyroid tumour appeared and caused rapid respiratory obstruction with death from asphyxia four months after the first symptoms of the illness.

We are indebted to Dr. Oddy for permission to publish the notes of the case. 


\section{REFERENCES.}

1. Hughes, B., Brit. Med. J., Lond., 1920, i, 362.

2. Blaxland, A. J., loc. cit., 454.

3. Schultz, O. T., Abt's Pediatrics, Philad., 1926, viii, 855.

4. Ewing, J., Neoplastic Diseases, Philad., 1928.

5. Moncrieff, A., \& Poynton, F. J., Proc. Roy. Soc. Med., Lond., 1929-30, XXIII, pt. I, 109.

6. Cattell, R. B., J. Am. Med. Ass., Chicago, 1931, xevii, 1761.

7. Idem., Surg. Clin., North Amer., Chicago, 1932, xii, 813.

8. Dunhill, T. P., Brit. J. Surg., Bristol, 1931, XIX, 83.

9. Griffith, J. P. C., \& Mitchell, A. G., Dis. of Infants and Child., Philad., 1933.

10. Pemberton, J., \& Dixon, C. F., Surg., Gynec. and Obst., Chicago, 1934, LVIII, 462.

11. Lee, F. C., J. Med. Ass. Georgia, Atlanta, 1934, XXIII, 123.

12. Schreiner, B., \& Murphy, W., Ann. Surg., Philad., 1934, XCIX, 1, 116.

13. Bérard, L., Goitres, Cancer Thyroidiens, Paris, 1908.

14. Müller, G., Loire Med., St. Etienne, 1913, XXXII, 227.

15. Meleney, F. L., Ann. Surg., Philad., 1922, LXXVI, 684.

16. Joll, C. A., Dis. of the Thyroid Gland, Lond., 1932. 